\title{
Low-dose interleukin-2 as a modulator of Treg homeostasis after HSCT: current understanding and future perspectives
}

\author{
Ken-ichi Matsuoka ${ }^{1}$
}

Received: 6 November 2017 / Revised: 24 November 2017 / Accepted: 30 November 2017 / Published online: 12 December 2017 (c) The Japanese Society of Hematology 2017

\begin{abstract}
$\mathrm{CD} 4^{+} \mathrm{CD} 25^{+} \mathrm{Foxp}^{+}$Treg is a functionally distinct subset of mature $\mathrm{T}$ cells with broad suppressive activity and has been shown to play an important role in the establishment of immune tolerance after HSCT. Altered cytokine environment in post-HSCT lymphopenia with a relative functional deficiency of IL-2 could hamper the reconstitution of Treg, leading to refractory GVHD. Based on the theory of low-dose IL-2 in which Treg can be selectively stimulated through the high-affinity IL-2 receptor, clinical studies have been conducted and demonstrated that low-dose IL-2 administration can restore Treg homeostasis and promote the expansion of this subset on the polymorphic processes of Treg reconstitution after HSCT. The new therapeutic indication of IL-2 for immune tolerance has launched in the field of HSCT and is spreading to the other fields including the treatment for autoimmune diseases. To further extend the indication of low-dose IL-2 to more patients with various immunological problems, the optimization of the timing and dosing of IL-2 intervention and the concomitant immune suppressive therapy according to each patient-based assessment are to be desired in the near future. Further prospective studies may facilitate the development of novel therapeutic algorithms for the effective and safe induction of immune tolerance after HSCT.
\end{abstract}

Keywords Interleukin- $2 \cdot$ Graft-versus-host disease $\cdot$ Regulatory $\mathrm{T}$ cell $\cdot$ Immune tolerance

\section{Introduction}

$\mathrm{CD} 4{ }^{+} \mathrm{CD} 25^{+} \mathrm{Foxp}^{+}$regulatory $\mathrm{T}$ cells (Tregs) are a functionally distinct subset of mature $\mathrm{T}$ cells with broad suppressive activity $[1,2]$ and play a critical role in the maintenance of peripheral tolerance. Lack of Tregs causes fatal autoimmunity in animal models and humans $[3,4]$ and even partial or relative deficiency of this subset often leads to various autoimmune diseases and inflammatory disorders [5]. Recent studies have shown that there are heterogeneous subpopulations of Treg and each subpopulation regulates concomitant effector cells [6] (Fig. 1). In the setting of allogeneic hematopoietic stem-cell transplantation (HSCT), Treg has been shown to play an important role

Ken-ichi Matsuoka

k-matsu@md.okayama-u.ac.jp

1 Department of Hematology and Oncology, Okayama University, 2-5-1 Shikata-cho, Kita-ku, Okayama 700-8558, Japan in the establishment of tolerance between host tissues and donor-derived immunity. Deficient recovery of Treg could be associated with the development of acute and chronic GVHD [7]. Therefore, the robust reconstitution of Treg is needed to establish a well-balanced immune system that can maintain appropriate levels of peripheral tolerance. Mature $\mathrm{T}$ cells in the stem-cell graft and newly differentiated $\mathrm{T}$ cell from the precursors recompose the system of immunity; however, the reconstructing process is subject to a variety of influences in the distinct post-HSCT environment (Fig. 2). In particular, the altered cytokine environment in severe lymphopenia where there are high amount of IL-7 and IL-15 and relative deficiency of interleukin-2 (IL-2) could hamper the favorable reconstitution of Treg, since IL-2 is the essential cytokine regulating Treg homeostasis [8, 10-12]. IL-2 is a kind of old cytokine and high-dose IL-2 administration has been used to stimulate activated T and NK cells for the purpose of enhancing anti-tumor immunity [13, 14]. In contrast, murine and clinical studies demonstrated that low-dose IL-2 administration was able to selectively stimulate Treg, 
Fig. 1 Lineage of $\mathrm{CD} 4^{+} \mathrm{T}$-cell subsets. Treg differentiates in thymus and emigrates to periphery. In periphery, naïve subset of Treg differentiates into the activated subsets, and thereafter the memory subsets. Each type of activated Treg exerts the suppression of the concomitant helper effector $\mathrm{T}$ cells. Tcon, conventional $\mathrm{CD} 4^{+} \mathrm{T}$ cell

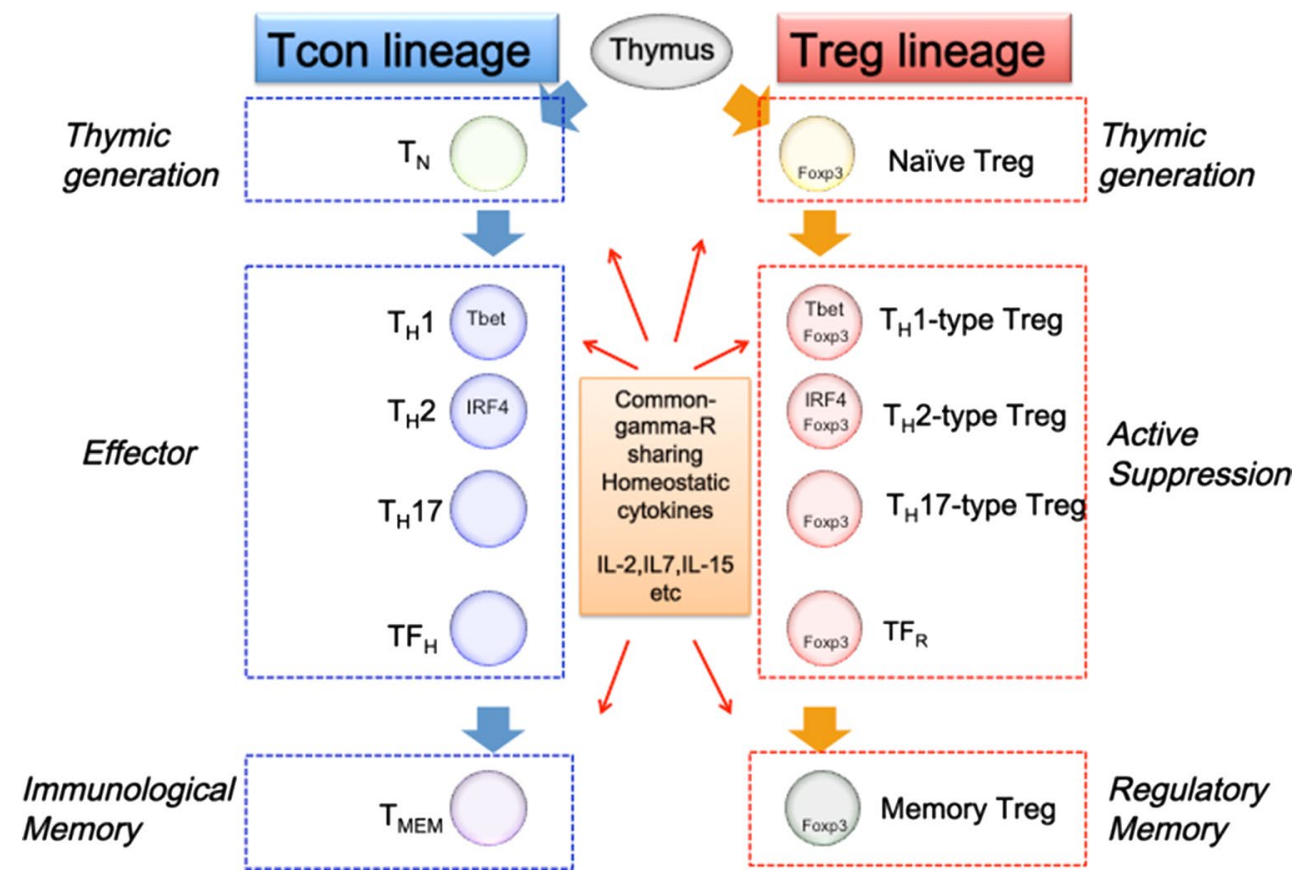

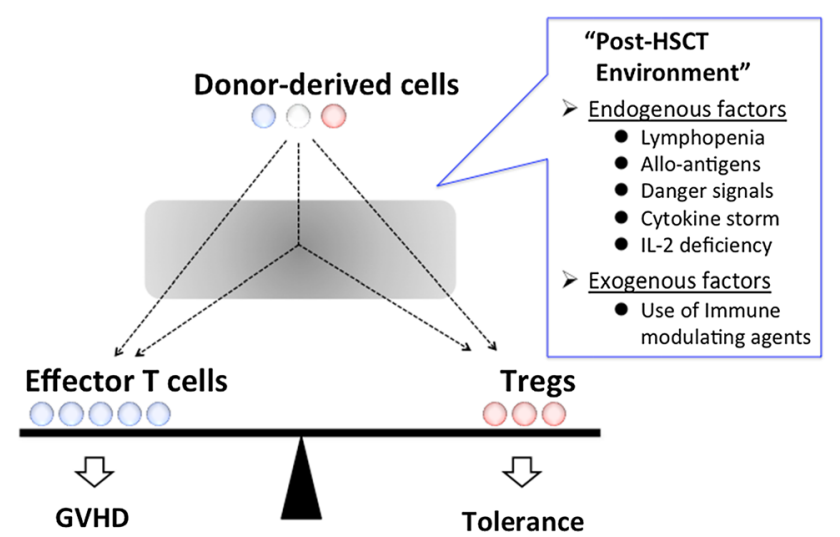

Fig. 2 Balancing between effector T cells and Treg cells in the distinct post-HSCT environment. Immune system in patients after HSCT is reconstructed by the donor-derived immune cells. Post-transplant environment has effects on the reconstitution of immune system. Deficient balance of Tregs may trigger the development of GVHD

since Treg possess the high-affinity IL-2 receptor, resulting in the induction of immune tolerance [12, 15-17]. The new therapeutic indication of IL-2 has been started in the field of HSCT and is spreading to the other fields including the treatment for autoimmune diseases $[18,19]$. In this review, we will first show our current understanding of the polymorphic process of Treg reconstitution after HSCT and then discuss the appropriate intervention in the altered Treg homeostasis in each distinct reconstituting phase by low-dose IL-2 for better outcomes of patients after HSCT. In the last part, the future perspectives and potentials of this therapy will be discussed.

\section{T-cell reconstitution after HSCT}

T-cell reconstitution after HSCT is the polymorphic and long-term process. In general, the initial phase of T-cell reconstitution is primarily dependent on peripheral expansion of mature $\mathrm{T}$ cells that are present in the donor stemcell graft $[20,21]$. This is promoted by lymphopeniarelated signals as well as stimulation by allo-antigens [8]. Hematopoietic stem cells also migrate to the thymus and differentiated $\mathrm{T}$ cells are exported into periphery. However, thymus-dependent generation of donor T cells is generally delayed and incomplete in adult patients because of natural thymic involution and damage resulting from high-dose chemotherapy and irradiation administered as parts of the conditioning regimen [22]. Once naïve T cells are exported into the periphery from thymus, these cells are subject to homeostatic signals that regulate the expansion and contraction of the T-cell population to maintain total numbers of T-cell subsets at appropriate levels in the circulation and peripheral lymphoid tissues. Although the transition of peripheral T-cell source from mature T cells in the stem-cell graft into thymic-generated naïve $T$ cells is commonly observed in each T-cell lineage after HSCT, each T-cell subsets are subject to distinct homeostatic controls in the periphery [23]. Particularly, Treg homeostasis appears to be distinct from conventional CD4 T cells (Tcon) and this may contribute to imbalance between Treg and Tcon $[24,25]$. We previously studied the long-term Treg reconstitution after clinical HSCT and reported that thymic generation of Treg was markedly impaired but that 
this subset maintained a significantly higher level of proliferation compared to Tcon [8]. Treg proliferation in vivo appeared to be driven primarily by CD4 lymphopenia. Importantly, high levels of Treg proliferation were counterbalanced by increased susceptibility to apoptosis in this subset. Our prospective monitoring study demonstrated the critical role of CD4 lymphopenia in the recovery of Treg and the selective peripheral depletion of Treg in response to this prolonged homeostatic pressure. The depletion of peripheral Treg was also associated with the development of chronic GVHD.

\section{Basic framework of Treg reconstitution}

Based on the findings, we here propose the basic framework of Treg reconstitution after HSCT, as shown in Fig. 2. It is constituted of four phases: Treg expansion, transition, repopulation, and maintenance. Though previous studies have suggested that host-type Treg showed a temporary expansion just after HSCT after nonmyeloablative conditioning, the kinetics of host-Treg after HSCT is left out from this schema to simply discuss the donor-Treg engrafting processes.

\section{Phase 1: expansion of graft-derived Treg}

In the first month post-HSCT, stem-cell graft-derived mature Tregs promptly expand in response to lymphopenia as well as allo-antigens. The expansion peaks around the first month after HSCT and appears to contract by activation-induced cell death (AICD). It still remains unclear whether some part of graft-derived Treg would survive or not as functionallymemory suppressor cells for a long time after HSCT [26].

\section{Phase 2: transition of peripheral Treg source}

The emergence of thymus-derived Treg is generally delayed because of thymic dysfunction after HSCT; therefore, the total Treg number in periphery once decreases after the contraction of graft-derived Tregs (transitional phase). The "dip" in Treg number in this phase may be associated with the onset of late-acute GVHD or overlap syndrome in the clinical situation.

\section{Phase 3: repopulation and relocation of thymus-generated Treg}

After a "dip" in Treg number in Phase 2, circulating Treg number increases and approaches to the normal range within a year. It is much faster than reconstitution of Tcon subsets those often reach a normal range over 2 years. Treg repopulation in this phase is mainly constituted by thymusgenerated Treg cells. Though thymic Treg generation is markedly impaired after HSCT, newly-generated Tregs keep the increased levels of proliferation over the phase. The proliferation is relatively aggressive as compared to other conventional $\mathrm{T}$ cells, resulting in the high levels of Treg/Tcon ratio and Treg/CD8T ratio in the phase [8] [9].

\section{Phase 4: maintenance of thymus-generated Treg}

Because only naïve Tregs are capable of aggressive proliferation, the stable emergence of naïve Treg from thymus can be thought to be critical for the maintenance of Treg homeostasis. Treg can repopulate by compensatory homeostatic proliferation in Phase 3 even in patients with severe thymic damage; however, high levels of Treg proliferation in the prolonged lymphopenia become to be counterbalanced by increased susceptibility to apoptosis 6-9 months after HSCT. Importantly, the peripheral depletion based on the abnormal homeostasis is observed just in Treg cells, not in other conventional $\mathrm{T}$ cells, resulting in the unbalance of lymphocyte subsets which provide a fundamental basis of the development of chronic GVHD [8, 27, 28].

\section{Intervention in Treg homeostasis by low-dose IL-2}

As mentioned, Treg homeostasis in the post-HSCT environment tends to be unstable. Recent clinical studies suggested that the use of several immune-modulating agents in the peri-transplant period, including sirolimus, thymoglobulin, azacitidine, ruxolitinib, and post-transplant cyclophosphamide (PT-Cy), might be associated with the relative increase of Treg subset in the early phase after HSCT. While these agents might increase Treg in an indirect fashion, exogenous low-dose IL-2 directly acts on Treg homeostasis in a Stat5-dependent manner and can increase the subset. Murine studies demonstrated that exogenous administration of low-dose IL-2 increased Treg and resulted in the improvement of autoimmune symptoms and GVHD [15, 29]. Analyses of the clinical samples from patients who received low-dose IL-2 to enhance GVL effect after post-transplant relapse elucidated that low-dose IL-2 increase NK cells as well as Treg cells [14, 30]. Based on these findings, immune tolerance-oriented indication of IL-2 in the clinical setting has launched.

Previous trials can be divided into two groups by timing and purpose of IL-2 intervention. One is for the purpose of treatment for developed GVHD symptoms in Phase 4, and the other is for the purpose of prophylaxis of GVHD during Phases 1-3. 


\section{Therapeutic intervention in Treg homeostasis by low-dose IL-2}

Previous studies with clinical samples have demonstrated that patients with chronic GVHD have lower levels of circulating Treg than patients without chronic GVHD [7] and the peripheral depletion of Treg in chronic GVHD patients appeared to be a consequence of abnormal Treg homeostasis in IL2-deficient lymphopenic condition [8]. To restore Treg homeostasis at chronic phase (that is, "maintenance phase" in Fig. 3), a phase 1 dose-escalation study aimed at exploring the maximum tolerated dose of daily low-dose subcutaneous IL-2 in patients with steroid-refractory chronic GVHD was conducted at Dana-Farber Cancer Institute [18, 19]. Twenty-nine patients were included, and the maximum tolerated dose of IL-2 was $1 \times 10^{6} \mathrm{IU} / \mathrm{m}^{2} .12$ of 23 evaluable patients achieved an objective partial response during the 8 weeks of IL-2 treatment. IL-2 therapy induced a series of changes in Treg homeostasis, including increased proliferation, increased thymic export, and enhanced resistance to apoptosis [19]. Based on these promising results, a Phase 2 study with low-dose $\left(1 \times 10^{6} \mathrm{IU} / \mathrm{m}^{2} /\right.$ day $)$ IL-2 was conducted and elucidated that clinical responders initiated IL-2 significantly earlier (508 versus 917 days after HSCT) and Treg:Tcon ratios $\geq 0.07$ at baseline and $\geq 0.2$ at week 1 also predicted clinical response [31,32].

In Japan, we got back to a preclinical study with murine model of IL-2 therapy to reconsider the optimum algorism

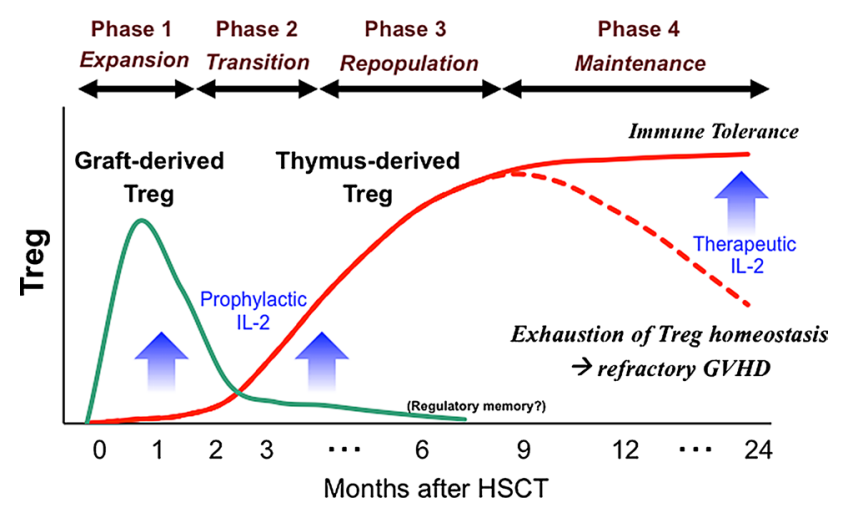

Fig. 3 Basic framework of Treg reconstitution. First, mature Tregs in the graft (shown in green) expand and contract (Phase 1). The number of Tregs transiently decreases between the contraction of graftderived Treg and the emergence of thymus-derived Treg (shown in red) (Phase 2). Thymus-derived Tregs aggressively proliferate in the lymphopenic condition and once reach to the normal level within a year (Phase 3). In cases with the stable maintenance of Treg homeostasis, patients can keep the immune tolerance (Red solid line). However, in cases with the exhausted Treg homeostasis, it may trigger the development of chronic GVHD (Red dot line) (Phase 4). Blue arrows indicate the uplifting effects of low-dose IL-2 on Treg in the multiple reconstituting phases of IL-2 intervention for safe and efficient Treg expansion and found that the daily administration might not be required and the intermittent administration within threshold could be sufficient for the maintenance of expanded Treg after the initial intensive IL-2 intervention. Based on the idea, we have designed and started a multicenter phase I/IIa clinical trial of low-dose IL-2 for patients with steroid-refractory cGVHD [33]. In our protocol, treatment is composed of two sequential phases: the induction phase and the maintenance phase. In the induction phase, IL-2 is subcutaneously administrated once per day for 4 weeks. In the subsequent maintenance phase, IL-2 is subcutaneously administrated three times per week for following 8 weeks. The study was just completed and data are being analyzed for publication and next pivotal phase of clinical trial.

\section{Prophylactic intervention in Treg homeostasis by low-dose IL-2}

The results from the Phase 2 study at Dana-Farber Cancer Institute suggest that low-dose IL-2 should start at the earlier timepoint when the rebuilding immunity still retains plasticity and the tissue damage remains mild. This may be related to the idea of the prophylactic use of low-dose IL-2. Several clinical trials of low-dose IL-2 for patients before developing GVHD have already conducted for the purpose of promoting the early Treg recovery and actively inducing tolerance (Fig. 3).

Huston group first tested the effect of prophylactic IL-2 for pediatric patients after HSCT [34]. IL-2 (1-2 $\times 10^{5} \mathrm{IU} /$ $\mathrm{m}^{2}$ /day) was daily administrated from days 30 to 120 , which resulted in Treg increase in the first month after the initiation of IL-2. Remarkably, no patients developed acute GVHD grades 2-4 and the incidence of virus infection was significantly decreased than the historical control. A group from China conducted a larger scale randomized trial, where patients in the IL-2 arm were compared with patients without IL-2 [35]. Patients in the IL-2 arm received subcutaneous injection of IL-2 $\left(1 \times 10^{6} \mathrm{IU} / \mathrm{m}^{2} /\right.$ day $)$ from day 60. IL-2 was administered daily for 14 days followed by a 14-day hiatus. Circulating Treg levels were elevated during the treatment periods. Incidence of chronic GVHD was significantly lower than control, while the cumulative incidence with the positive minimum residual disease (MRD) test was significantly higher in IL-2 cohort compared with the control cohort. Betts et al. conducted the very early IL-2 administration trial [36]. 20 patients received IL-2 $\left(2 \times 105 \mathrm{IU} / \mathrm{m}^{2} /\right.$ day), thrice weekly, from days 0 to +90 . IL-2 administration resulted in the increase of Treg in the first month; however, it led to a fall in Tregs by day 90 and did not reduce acute or chronic GVHD. Interestingly, patients who discontinued 
IL-2 before day 100 showed a trend toward less acute GVHD grades $2-4$.

These findings from the completed studies suggest that the prophylactic administration of low-dose IL-2 can successfully promote the early Treg expansion and it appears to contribute the suppression of acute and chronic GVHD. Since allo-stimulation is still aggressive and also the absolute number of Treg is much fewer in this prophylactic phase (Phases 1-3 in Fig. 2) as compared with the chronic phase (Phase 4 in Fig. 2), the delicate optimizing of IL-2 dosing is thought to be the key to sustain lasting Treg levels and induce tolerance $[37,38]$. On the other hand, one study reported the significant increase of positive MRD test in patients received IL-2 prophylactically, suggesting that IL-2 might affect GVL effect at least partially. For this reason, it might be better to carefully follow the long-term influence of the early Treg modification by low-dose IL-2.

In the completed three trials introduced above, the enrolled patients were basically recipients of transplantation from HLA-matched donors. NIH group is conducting a clinical trial to extend the indication of prophylactic low-dose IL-2 toward haplo-identical transplantation. Patients receive haplo-identical donor grafts with posttransplant cyclophosphamide followed by daily administration of low-dose IL-2 $\left(1 \times 10^{5} \mathrm{IU} / \mathrm{m}^{2}\right)$ for 12 weeks starting day 1 (ClinicalTrials. gov Identifier: NCT02226861). In this setting, it would be theoretically expected that NK cell-based anti-tumor immunity could be enhanced with exogenous IL-2, leading to a possibility of clearly separating GVL from GVHD [16].

\section{Future perspectives}

Clinical studies of low-dose IL-2 in the past decade have shown the feasibility and the efficacy of this treatment. To extend the indication of low-dose IL-2 to more patients with various immunological problems such as severe thymic involution, malignant cancer, and refractory autoimmune diseases, several combination therapies with IL-2 were worthy to be taken into consideration.

\section{Low-dose IL-2 combined with donor-Treg infusion}

It has been demonstrated that thymic generation of Tregs was minimal, while Tregs reconstituted by peripheral expansion of mature Tregs present in the graft and exhibited a predominantly activated/memory phenotype [8]. This may be particularly true in older patients and in patients with the past history of aggressive acute GVHD. Because only naïve Treg has robust proliferative potential and can respond promptly to exogenous IL-2, lack of thymic generation of naïve Treg results in the attenuation of the effect of low-dose IL-2 to increase Treg. From the point of view, in such cases with severe thymic damage, combination therapy of the infusion of fresh Treg from donor and the subsequent low-dose IL-2 administration is thought to be logically true way (Fig. 4). Phase 1 study aimed at assessing the feasibility and efficacy of Treg infusion combined with low-dose IL-2 in patients with steroidrefractory chronic GVHD is currently ongoing (ClinicalTrials.gov Identifier: NCT01937468).

\section{Low-dose IL-2 combined with checkpoint blockade}

We recently demonstrated that PD-1 is a critical homeostatic regulator for Treg by modulating proliferation and apoptosis during IL-2 therapy [39]. This study showed that exogenous IL-2 promptly induces the expression of PD-1 particularly on central-memory Tregs and increased PD-1 expression was maintained during IL-2 therapy. Of note, PD-1 blockade negated the effects of IL-2, promoted Treg apoptosis, and reduced Treg numbers in vivo. In HSCT patients after receiving PD-1 blockade, it might be needed to consider the indication of low-dose IL-2 with caution. However, if viewed from the opposite side, it may means that PD-1 inhibition of Tregs may provide an additional mechanism, whereby PD-1 blockade promotes effective tumor immunity in patients with cancer.

\section{Application for autoimmune diseases}

Chronic GVHD is well known to have clinical features of autoimmune diseases those are also often associated with lymphopenia. This may suggest that the abnormal response of Treg to homeostatic pressure in the prolonged lymphopenic environment may provide a common pathologic mechanism for chronic GVHD and other autoimmune diseases. Considering the broad clinical relevance of this mechanism, the restoration of normal Treg homeostasis using low-dose IL-2 could be worth considering for the re-induction of tolerance in patients with autoimmunity as well as GVHD. So far, clinical trials for various autoimmune diseases have been performed and promising results were reported in some diseases including systemic lupus erythematosus (SLE) and type-1 diabetes, as shown in Table 1 [40-44]. Ongoing trials are recruiting patients with other autoimmune diseases such as rheumatoid arthritis, Crohn's disease, ulcerative colitis, and so on. As Satake et al. suggested, the immune suppressive agents concomitantly used with IL-2 and the levels of active inflammation should be taken into account for the strategy of inducing tolerance in autoimmune diseases $[37,38,45]$. 
Fig. 4 Classification of Tregbased therapy for patients after HSCT. 3 concepts of Treg-based therapy are shown. Red-colored cells indicate Tregs. a Ex vivo expanded Treg infusion: Donor-derived Tregs are expanded ex vivo and then infused to the patients. b Low-dose IL-2 therapy: Low doses of IL-2 are administered to patients to increase Treg in vivo. c Treg infusion followed by low-dose IL-2: donorderived Tregs are enriched (without ex vivo expansion) and then infused to the patients. Subsequently, low-doses of IL-2 are administrated to increase the infused Treg in vivo

\section{(A) ex vivo-expanded Treg infusion}

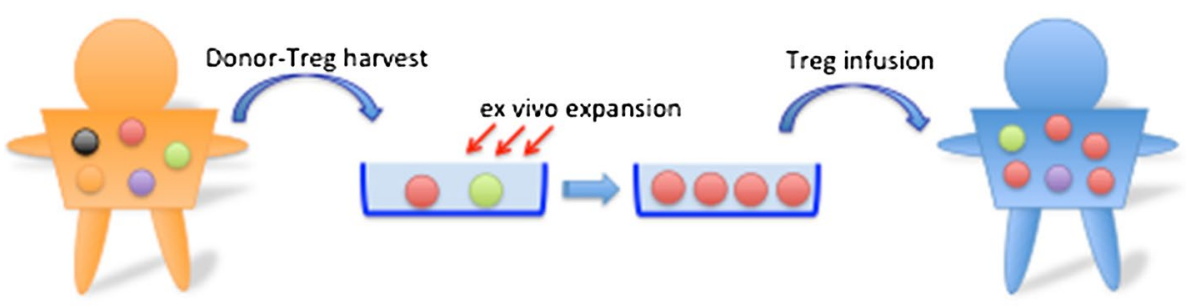

(B) Low-dose IL-2 therapy
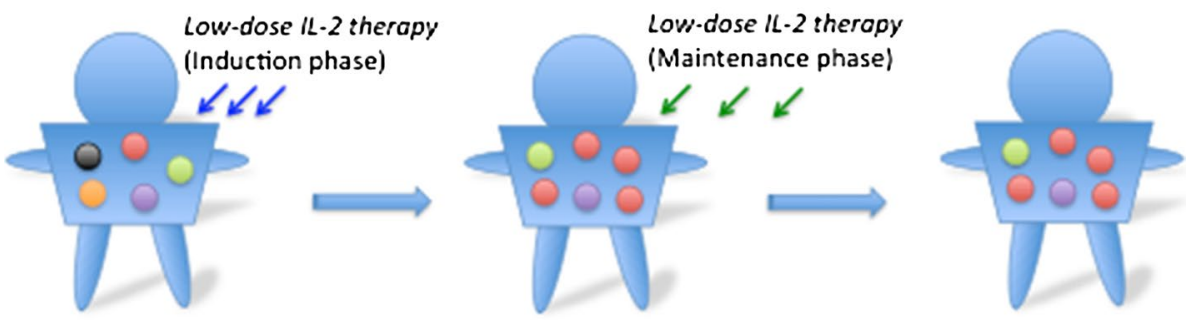

(C) Treg infusion followed by low-dose IL-2

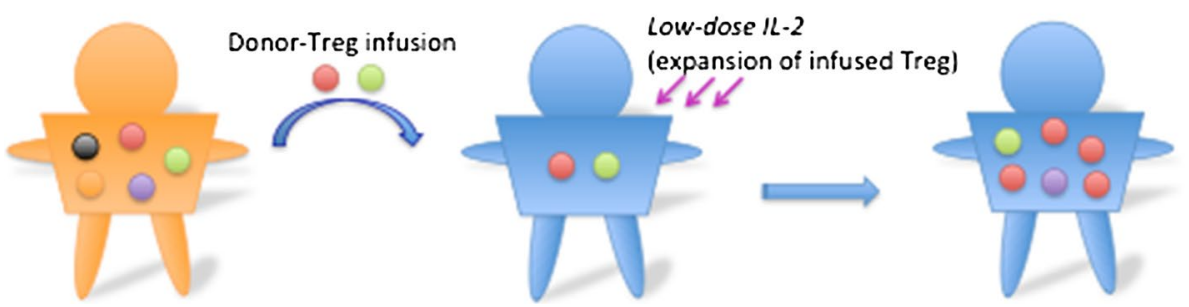

Table 1 Completed clinical trials of low-dose IL-2 for GVHD and other autoimmune diseases

\begin{tabular}{|c|c|c|c|}
\hline Disease/Purpose & Schedule of IL-2 administration & Efficacy & Refs. \\
\hline Steroid-refractory chronic GVHD & $1 \times 10^{6} \mathrm{IU} / \mathrm{m}^{2} /$ day, daily administration for $8-12$ weeks & $52-61 \%$ clinical response & {$[18,31]$} \\
\hline GVHD prophylaxis & $\begin{array}{l}1-2 \times 10^{5} \mathrm{IU} / \mathrm{m}^{2} / \text { day, daily administration from day } 30 \\
\text { to day } 120\end{array}$ & No grade II-IV aGVHD & [34] \\
\hline GVHD prophylaxis & $\begin{array}{l}1 \times 10^{6} \mathrm{IU} / \mathrm{m}^{2} / \text { day, daily administration for } 14 \text { days fol- } \\
\text { lowed by a } 14 \text {-day hiatus, from day } 60\end{array}$ & Less moderate-to-severe chronic GVHD & [35] \\
\hline GVHD prophylaxis & $\begin{array}{l}2 \times 10^{5} \mathrm{IU} / \mathrm{m}^{2} / \text { day, administration thrice weekly, from } \\
\text { days } 0 \text { to } 90\end{array}$ & $\begin{array}{l}\text { Less grade II-IV aGVHD (if IL-2 } \\
\text { discontinued early) }\end{array}$ & [36] \\
\hline $\mathrm{HCV}$ vasculitis & $\begin{array}{l}1-3 \times 10^{6} \mathrm{IU} / \mathrm{m}^{2} / \text { day from days } 1 \text { to } 5 \text { every } 21 \text { days, } 4 \\
\text { courses }\end{array}$ & $90 \%$ Clinical response & [40] \\
\hline Systemic lupus erythematosus & $\begin{array}{l}1 \times 10^{6} \mathrm{IU} / \mathrm{m}^{2} / \text { day every other day for } 14 \text { days, } 3-6 \\
\text { courses }\end{array}$ & 95\% Clinical response & [43] \\
\hline Alopecia areata & $\begin{array}{l}1-3 \times 10^{6} \mathrm{IU} / \mathrm{m}^{2} / \text { day from days } 1 \text { to } 5 \text { every } 21 \text { days, } 4 \\
\text { courses }\end{array}$ & $80 \%$ Clinical response & [42] \\
\hline Type1-diabetus & $0.3-3 \times 10^{6} \mathrm{IU} / \mathrm{m}^{2} /$ day, daily administration for 5 days & Selective Treg increase & [41] \\
\hline
\end{tabular}

\section{Conclusion}

The present review provides a summary of the previous studies of low-dose IL-2 therapy for patient after allogeneic HSCT. New indication of IL-2 for immune tolerance was proposed from the field of HSCT and thereafter extending to the field of autoimmunity within just a few years, suggesting the study of clinical GVHD could be an important platform to develop new cellular therapy for 
various autoimmune diseases widely. Treg reconstitution after HSCT is basically polymorphic and varies in each patient; therefore, the appropriate timing and dosing of IL-2 intervention should be considered according to each patient-based immune monitoring in the near future. Further prospective studies may facilitate the development of novel therapeutic algorithms for the effective and safe induction of immune tolerance after HSCT.

\section{References}

1. Sakaguchi S, Sakaguchi N, Asano M, Itoh M, Toda M. Immunologic self-tolerance maintained by activated $\mathrm{T}$ cells expressing IL-2 receptor alpha-chains (CD25). Breakdown of a single mechanism of self-tolerance causes various autoimmune diseases. J Immunol. 1995;155(3):1151-64.

2. Hori S, Nomura T, Sakaguchi S. Control of regulatory T cell development by the transcription factor Foxp3. Science. 2003;299(5609):1057-61.

3. Brunkow ME, Jeffery EW, Hjerrild KA, Paeper B, Clark LB, Yasayko SA, et al. Disruption of a new forkhead/winged-helix protein, scurfin, results in the fatal lymphoproliferative disorder of the scurfy mouse. Nat Genet. 2001;27(1):68-73

4. Bennett CL, Christie J, Ramsdell F, Brunkow ME, Ferguson PJ, Whitesell $\mathrm{L}$, et al. The immune dysregulation, polyendocrinopathy, enteropathy, X-linked syndrome (IPEX) is caused by mutations of FOXP3. Nat Genet. 2001;27(1):20-1.

5. Humblet-Baron S, Sather B, Anover S, Becker-Herman S, Kasprowicz DJ, Khim S, et al. Wiskott-Aldrich syndrome protein is required for regulatory $\mathrm{T}$ cell homeostasis. J Clin Invest. 2007;117(2):407-18.

6. Zhou L, Chong MM, Littman DR. Plasticity of CD4+ T cell lineage differentiation. Immunity. 2009;30(5):646-55.

7. Zorn E, Kim HT, Lee SJ, Floyd BH, Litsa D, Arumugarajah S, et al. Reduced frequency of FOXP $3{ }^{+} \mathrm{CD} 4{ }^{+} \mathrm{CD} 25^{+}$regulatory $\mathrm{T}$ cells in patients with chronic graft-versus-host disease. Blood. 2005;106(8):2903-11

8. Matsuoka K, Kim HT, McDonough S, Bascug G, Warshauer B, Koreth $\mathrm{J}$, et al. Altered regulatory $\mathrm{T}$ cell homeostasis in patients with CD4+ lymphopenia following allogeneic hematopoietic stem cell transplantation. J Clin Invest. 2010;120(5):1479-93.

9. Alho AC, Kim HT, Chammas MJ, Reynolds CG, Matos TR, Forcade E, et al. Unbalanced recovery of regulatory and effector $\mathrm{T}$ cells after allogeneic stem cell transplantation contributes to chronic GVHD. Blood. 2016;127(5):646-57.

10. Setoguchi R, Hori S, Takahashi T, Sakaguchi S. Homeostatic maintenance of natural Foxp3(+) CD25(+) CD4(+) regulatory T cells by interleukin (IL)-2 and induction of autoimmune disease by IL-2 neutralization. J Exp Med. 2005;201(5):723-35.

11. Pierson W, Cauwe B, Policheni A, Schlenner SM, Franckaert D, Berges $\mathbf{J}$, et al. Antiapoptotic Mcl-1 is critical for the survival and niche-filling capacity of Foxp3(+) regulatory T cells. Nat Immunol. 2013;14(9):959-65.

12. Toomer KH, Malek TR. Cytokine signaling in the development and homeostasis of regulatory T cells. Cold Spring Harb Perspect Biol. 2017. https://doi.org/10.1101/cshperspect.a028597

13. Cheever MA, Thompson JA, Peace DJ, Greenberg PD. Potential uses of interleukin 2 in cancer therapy. Immunobiology. 1986;172(3-5):365-82.

14. Soiffer RJ, Murray C, Gonin R, Ritz J. Effect of low-dose Interleukin-2 on disease relapse after T-cell-depleted allogeneic bone marrow transplantation. Blood. 1994;84(3):964-71.
15. Sykes M, Romick ML, Sachs DH. Interleukin 2 prevents graft-versus-host disease while preserving the graft-versusleukemia effect of allogeneic T cells. Proc Natl Acad Sci USA. 1990;87(15):5633-7.

16. Ito S, Bollard CM, Carlsten M, Melenhorst JJ, Biancotto A, Wang $\mathrm{E}$, et al. Ultra-low dose Interleukin-2 promotes immune-modulating function of regulatory $\mathrm{T}$ cells and natural killer cells in healthy volunteers. Mol Ther. 2014;22(7):1388-95.

17. Klatzmann D, Abbas AK. The promise of low-dose Interleukin-2 therapy for autoimmune and inflammatory diseases. Nat Rev Immunol. 2015;15(5):283-94.

18. Koreth J, Matsuoka K, Kim HT, McDonough SM, Bindra B, Alyea EP 3rd, et al. Interleukin-2 and regulatory T cells in graftversus-host disease. N Engl J Med. 2011;365(22):2055-66.

19. Matsuoka K, Koreth J, Kim HT, Bascug G, McDonough S, Kawano Y, et al. Low-dose Interleukin-2 therapy restores regulatory $\mathrm{T}$ cell homeostasis in patients with chronic graft-versus-host disease. Sci Transl Med. 2013;5(179):179ra43.

20. Mackall CL, Hakim FT, Gress RE. T-cell regeneration: all repertoires are not created equal. Immunol Today. 1997;18(5):245-51.

21. Mackall CL, Gress RE. Pathways of T-cell regeneration in mice and humans: implications for bone marrow transplantation and immunotherapy. Immunol Rev. 1997;157:61-72.

22. Williams KM, Hakim FT, Gress RE. T cell immune reconstitution following lymphodepletion. Semin Immunol. 2007;19(5):318-30.

23. Surh CD, Sprent J. Homeostasis of naive and memory T cells. Immunity. 2008;29(6):848-62.

24. Vukmanovic-Stejic M, Zhang Y, Cook JE, Fletcher JM, McQuaid A, Masters JE, et al. Human CD4+ CD25hi Foxp3+ regulatory T cells are derived by rapid turnover of memory populations in vivo. J Clin Invest. 2006;116(9):2423-33.

25. Sakaguchi S, Yamaguchi T, Nomura T, Ono M. Regulatory T cells and immune tolerance. Cell. 2008;133(5):775-87.

26. Rosenblum MD, Gratz IK, Paw JS, Lee K, Marshak-Rothstein A, Abbas AK. Response to self antigen imprints regulatory memory in tissues. Nature. 2011;480(7378):538-42.

27. Kawano Y, Kim HT, Matsuoka K, Bascug G, McDonough S, Ho VT, et al. Low telomerase activity in CD4+ regulatory $\mathrm{T}$ cells in patients with severe chronic GVHD after hematopoietic stem cell transplantation. Blood. 2011;118(18):5021-30.

28. Murase K, Kim HT, Bascug OR, Kawano Y, Ryan J, Matsuoka K, et al. Increased mitochondrial apoptotic priming of human regulatory $\mathrm{T}$ cells after allogeneic hematopoietic stem cell transplantation. Haematologica. 2014;99(9):1499-508.

29. Tang Q, Adams JY, Penaranda C, Melli K, Piaggio E, Sgouroudis $\mathrm{E}$, et al. Central role of defective Interleukin-2 production in the triggering of islet autoimmune destruction. Immunity. 2008;28(5):687-97.

30. Zorn E, Mohseni M, Kim H, Porcheray F, Lynch A, Bellucci R, et al. Combined CD4+ donor lymphocyte infusion and low-dose recombinant IL-2 expand FOXP3+ regulatory T cells following allogeneic hematopoietic stem cell transplantation. Biol Blood Marrow Transplant. 2009;15(3):382-8.

31. Koreth J, Kim HT, Jones KT, Lange PB, Reynolds CG, Chammas MJ, et al. Efficacy, durability, and response predictors of low-dose Interleukin-2 therapy for chronic graft-versus-host disease. Blood. 2016;128(1):130-7.

32. Hirakawa M, Matos TR, Liu H, Koreth J, Kim HT, Paul NE, et al. Low-dose IL-2 selectively activates subsets of CD4+ Tregs and NK cells. JCI Insight. 2016;1(18):e89278.

33. Asano T, Matsuoka KI, Iyama S, Ohashi K, Inamoto Y, Ohwada $\mathrm{C}$, et al. Phase I/IIa study of low dose subcutaneous Interleukin-2 (IL-2) for treatment of refractory chronic graft versus host disease. Acta Med Okayama. 2016;70(5):429-33.

34. Kennedy-Nasser AA, Ku S, Castillo-Caro P, Hazrat Y, Wu MF, Liu H, et al. Ultra low-dose IL-2 for GVHD prophylaxis after 
allogeneic hematopoietic stem cell transplantation mediates expansion of regulatory $\mathrm{T}$ cells without diminishing antiviral and antileukemic activity. Clin Cancer Res. 2014;20(8):2215-25.

35. Zhao XY, Zhao XS, Wang YT, Chen YH, Xu LP, Zhang XH, et al. Prophylactic use of low-dose Interleukin-2 and the clinical outcomes of hematopoietic stem cell transplantation: a randomized study. Oncoimmunology. 2016;5(12):e1250992.

36. Betts BC, Pidala J, Kim J, Mishra A, Nishihori T, Perez L, et al. IL-2 promotes early Treg reconstitution after allogeneic hematopoietic cell transplantation. Haematologica. 2017;102(5):948-57.

37. Satake A, Schmidt AM, Archambault A, Leichner TM, Wu GF, Kambayashi T. Differential targeting of IL-2 and T cell receptor signaling pathways selectively expands regulatory $\mathrm{T}$ cells while inhibiting conventional T cells. J Autoimmun. 2013;44:13-20.

38. Satake A, Schmidt AM, Nomura S, Kambayashi T. Inhibition of calcineurin abrogates while inhibition of mTOR promotes regulatory $\mathrm{T}$ cell expansion and graft-versus-host disease protection by IL-2 in allogeneic bone marrow transplantation. PLoS One. 2014;9(3):e92888.

39. Asano T, Meguri Y, Yoshioka T, Kishi Y, Iwamoto M, Nakamura $\mathrm{M}$, et al. PD-1 modulates regulatory T-cell homeostasis during low-dose Interleukin-2 therapy. Blood. 2017;129(15):2186-97.
40. Saadoun D, Rosenzwajg M, Joly F, Six A, Carrat F, Thibault V, et al. Regulatory T-cell responses to low-dose Interleukin- 2 in HCV-induced vasculitis. N Engl J Med. 2011;365(22):2067-77.

41. Hartemann A, Bensimon G, Payan CA, Jacqueminet S, Bourron $\mathrm{O}$, Nicolas $\mathrm{N}$, et al. Low-dose interleukin 2 in patients with type 1 diabetes: a phase $1 / 2$ randomised, double-blind, placebo-controlled trial. Lancet Diabetes Endocrinol. 2013;1(4):295-305.

42. Castela E, Le Duff F, Butori C, Ticchioni M, Hofman P, Bahadoran $\mathrm{P}$, et al. Effects of low-dose recombinant interleukin 2 to promote T-regulatory cells in alopecia areata. JAMA Dermatol. 2014;150(7):748-51.

43. He J, Zhang X, Wei Y, Sun X, Chen Y, Deng J, et al. Low-dose Interleukin-2 treatment selectively modulates CD4(+) T cell subsets in patients with systemic lupus erythematosus. Nat Med. 2016;22(9):991-3.

44. Spence A, Tang Q. Restoring regulatory T cells in type 1 diabetes. Curr Diabetes Rep. 2016;16(11):110.

45. Zou T, Satake A, Corbo-Rodgers E, Schmidt AM, Farrar MA, Maltzman JS, et al. Cutting edge: IL-2 signals determine the degree of TCR signaling necessary to support regulatory $\mathrm{T}$ cell proliferation in vivo. J Immunol. 2012;189(1):28-32. 